\title{
Telarca Precoz
}

\section{Dr. Alberto Duarte-Contreras*}

La telarca es el inicio del desarrollo de las glándulas mamarias $y$ se presenta normalmente por encima de los ocho años; con ella empieza el período prepuberal (15).

Wilkins Ilamó en 1945 "telarca precoz" o "telarca prematura" al desarrollo de lás glándulas mamarias en niñas menores de ocho años que no presentasen ninguna otra manifestación de maduración sexual (24). Talbot y colaboradores la llamaron "ginarca prematura" o "mamoplasia precoz" (22). Caufriez le dice "ginecomastia aislada" (4). Wilkins fue el primero en hablar de este tópico (24); Bronstein y Cassorla presentaron un segundo estudio en 1946 (2).

En veinte trabajos de la literatura occidental publicados entre 1947 y 1967 se describieron 205 casos (22). No conocemos publicación alguna nacional sobre el tema, pero es lógico pensar que muchos pediatras y médicos en general han observado este fenómeno tanto en niñas de clientela hospitalaria como privada.

* Médico de la Consulta Externa de Ginecología Pediátrica del Hospital San Juan de Dios, Cúcuta.
Se presenta a cualquier edad antes de los ocho años si bien se le observa con mayor frecuencia entre uno y tres años (3).

Se desconoce su incidencia pero seguramente es más frecuente de lo que se cree, tanto más cuanto que hay un buen número de casos en los cuales el desarroIlo no es prominente, motivo por el cual pasan desapercibidos. La incidencia es mayor en el grupo de niñas que presentaron hipertrofia mamaria neonatal.

Aun cuando es un fenómeno transitorio, en oportunidades puede durar varios años y aún persistir hasta la pubertad (12), como ocurrió en dos de nuestras pacientes. Por lo general la hipertrofia tiende a conservarse más tiempo cuando la aparición es temprana y pasa con cierta rapidez cuando la iniciación es tardía Por lo general el crecimiento no es exagerado si bien puede alcanzar tamaños considerables.

Hemos hecho el seguimiento a doce niñas con telarca precoz en la Consul ta de Ginecología Pediátrica del Hospital San Juan de Dios de Cúcuta y en nuestra clientela particular en el período 1970 - 1986 (ver cuadro 1). 
CUADRO 1

Telarca Prematura

\begin{tabular}{|c|c|c|c|c|c|c|c|c|c|c|c|}
\hline No. & \multicolumn{2}{|c|}{$\begin{array}{l}\text { Edad al } \\
\text { inicio }\end{array}$} & \multicolumn{2}{|c|}{$\begin{array}{l}\text { Edad al } \\
\text { examen }\end{array}$} & Carpograma & Talla & $\begin{array}{c}\text { Ecografía } \\
\text { pélvica }\end{array}$ & $\begin{array}{l}\text { Urocito- } \\
\text { grama }\end{array}$ & $\begin{array}{l}\text { Unila- } \\
\text { teral }\end{array}$ & $\begin{array}{l}\text { Bila- } \\
\text { teral }\end{array}$ & Evolución \\
\hline 1 & 1 año & $7 \mathrm{~m}$. & 2 añ & $4 \mathrm{~m}$. & & ( & & & & + & 2 años después involución parcial \\
\hline 2 & 2 años & & 3 añ & $3 \mathrm{~m}$. & & normal & & negativo & & + & 2 años $5 \mathrm{~m}$. después involución parcial \\
\hline 3 & 5 años & & 6 año & & normal & normal & & negativo & & + & sin cambio 6 años después \\
\hline 4 & & $4 \mathrm{~m}$. & & $8 \mathrm{~m}$. & & normal & & negativo & + & & 3 años después desarrolló la otra mama; \\
\hline & & & & & & & & & & & 2 años más tarde involución parcial \\
\hline 5 & 1 año & & 1 año & $9 \mathrm{~m}$. & & normal & & negativo & & + & 3 años después involución parcial \\
\hline 6 & & $3 \mathrm{~m}$. & 2 año & $7 \mathrm{~m}$. & & normal & & negativo & & + & 2 años $4 \mathrm{~m}$. después involución parcial \\
\hline 7 & 2 años & & 2 año & $4 \mathrm{~m}$. & & normal & & negativo & & + & 4 años después involución parcial \\
\hline 8 & 5 años & $4 \mathrm{~m}$. & 6 año & & normal & normal & normal & negativo & + & & sin cambio 4 años después \\
\hline 9 & & $5 \mathrm{~m}$. & & $10 \mathrm{~m}$. & & normal & & negativo & & + & 3 años después involución total \\
\hline 10 & 1 año & $9 \mathrm{~m}$. & 2 año & $5 \mathrm{~m}$. & & normal & & negativo & & + & 1 año $8 \mathrm{~m}$. después involución parcial \\
\hline 11 & 2 años & $5 \mathrm{~m}$. & 3 año & $4 \mathrm{~m}$. & & normal & normal & negativo & & + & sin cambio 4 años después \\
\hline 12 & 1 año & $1 \mathrm{~m}$. & 1 año & $7 \mathrm{~m}$. & & normal & & negativo & & + & 2 años $9 \mathrm{~m}$. después involución total \\
\hline
\end{tabular}

\section{HALLAZGOS}

\section{EDAD}

Las doce pacientes iniciaron el desarrollo mamario entre los tres meses y los cinco años cuatro meses (23 meses en promedio), y el día de la primera consulta tenían entre ocho meses y seis años.

El motivo de consulta fue el inicio del desarrollo uni o bilateral de las glándulas mamarias, hecho que llamaba la atención de las madres, dada la corta edad de las niñas.

\section{ANTECEDENTES}

Ninguna niña tuvo el antecedente de administración directa local u oral de estrógenos, ni indirecta por medio de cremas cosméticas enriquecidas con estrógenos usadas por algunas madres.

Ninguna madre había presentado desarrollo mamario prematuro ni se habían observado casos similares en la familia. A dos niñas les habían practicado mamografía para descartar etiología tumoral.

\section{EXAMEN CLINICO}

Ninguna niña presentó vello pubiano ni axilar, ni estrogenización de genitales externos. La talla fue siempre normal. La maduración esquelética investigada por el carpograma a las niñas 3 y 8 fue acorde con la edad cronológica. El urocitograma fue estrogénico en todas las pacientes.

En una niña de ocho meses y en otra de seis años (casos 4 y 8 ) se encontró desarrollo unilateral derecho; la de ocho meses inició el crecimiento de la mama izquierda tres años más tarde y dos años después presentó involución bilateral, la que se verificó parcialmente. La niña 9 tuvo un desarrollo bilateral pero asimétrico. Tres años después involucionó totalmente. El diámetro transversal mamario osciló entre 5 y 9 centímetros en todas las pacientes. 


\section{CONTROLES}

A todas las pacientes se les practicaron dos controles cada año durante tres a seis años consecutivos; en cuatro no se observó modificación del volumen; en ocho hubo un aumento discreto de 1 a 3 centímetros. En ninguna hubo desarrollo de los caracteres sexuales en los diferentes controles. Las aréolas no registraron cambio alguno; conservaron tanto el color como el tamaño infantil. Los pezones tampoco sufrieron transformación alguna. Ocho años después de la primera consulta, dos niñas son púberes con órganos sexuales normales y con desarrollo mamario normal.

No practicamos dosificación de FSH ni de LH ni de estradiol. Para investigar el grado de estrogenización nos valemos de la citología exfoliativa funcional, a la que damos plena validez.

\section{COMENTARIOS}

La telarca precoz es una hiperplasia ma. maria aislada en niñas menores de ocho años que no se acompaña de ningún otro signo de maduración sexual. Es un trastorno en el que no se presenta evidencia alguna de malignidad ni de displasia (ver figura 1).

Se desconoce la causa de la telarca precoz. Para Wilkins (24), Talbot (22), Capraro (3), Arcangeli (1) y otros autores (23), obedece a una rara sensibilidad del receptor mamario a tasas muy bajas de estrógenos circulantes, insuficientes para lograr cambios hormonales en los tejidos genitales infantiles.

Otros autores creen que puede ser la respuesta a la presencia de folículos de De
FIGURA No. 1

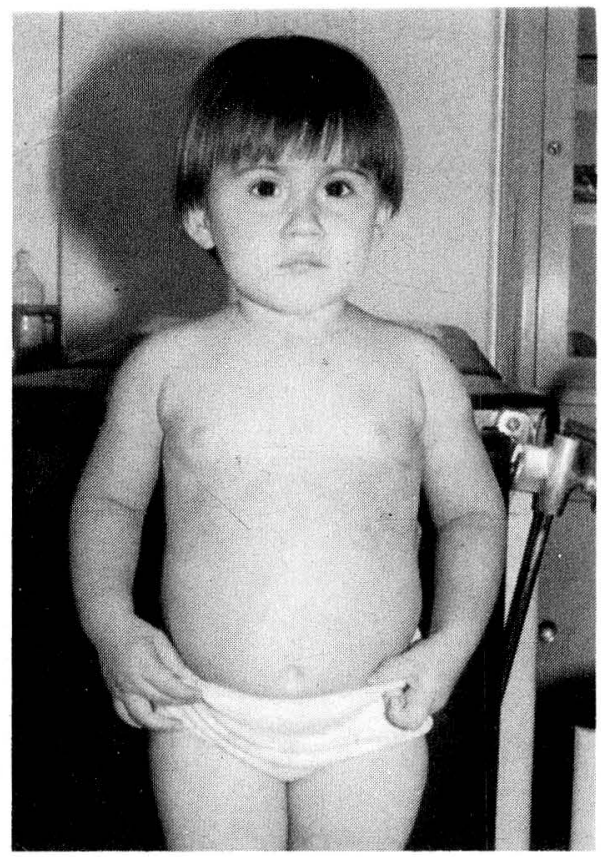

Telarca precoz en una niña de 2 años 7 meses; se habia iniciado a la edad de tres meses (caso 6).

Graff luteinizados o quísticos y se basan en la observación de que el desarrollo mamario desaparece al extirpar estos quistes o agrandamientos ováricos o cuando los folículos se hacen atrésicos $(5,12,18$, 20).

Aun cuando aparentemente la mama tiene un umbral de respuesta a los estrógenos inferior al de los demás órganos sexuales femeninos, posiblemente en algunas niñas durante la primera infancia se sensibiliza aún más a los bajos niveles estrógenicos circulantes y por ello al menor aumento que se presente por una causa cualquiera interna desconocida, desencadena el inicio de la hiperplasia (7). 
Gorins sugiere la puesta en acción prematura y pasajera de un centro hipotalámico particular que ocasionaría el desarrollo de las glándulas mamarias (13).

Se ha descrito consecutiva a la ingestión constante de sopa de pollo enlatada, para cuya elaboración se habían usado capones levantados con nutrientes estrogenizados (24).

No se ha podido demostrar ingerencia alguna de la alimentación materna. Tampoco se conoce predisposición fami$\operatorname{liar}(8)$.

Se puede encontrar desarrollo mamario persistente en una recién nacida: estos raros casos están siempre ligados a la pubertad precoz y se acompañan de frotis vaginal estrogénico $(1,13)$.

Dos o tres días después del nacimiento durante la "crisis genital de la recién nacida", las glándulas mamarias, que son un excelente receptor hormonal, sufren en el $80 \%$ de las niñas cambios importantes como respuesta normal a la estimulación pasiva hormonal recibida al final del embarazo tanto materna como placentaria. Este aumento transitorio del tamaño, es conocido como "hipertrofia mamaria de la recién nacida", y se acompaña en oportunidades de una secreción clara, mezcla de calostro y leche que escurre por el pezón, llamada "leche de brujas". Esta hipertrofia es bilateral pero puede ser unilateral si hay formación imperfecta de uno de los botones mamarios y jamás se encuentra en recién nacidas con peso inferior a los 1.500 gramos (6). Esta hipertrofia es efímera y sólo dura una a dos semanas. La glándula queda reducida luego a un pequeño nódulo y entra en un estado de reposo e inactividad que dura hasta la pubertad. Si la hipertrofia persiste se debe investigar una causa de estimulación estrogénica como un tumor ovárico secretante de estrógenos, o un galactocele, o un absceso, estos dos últimos unilaterales. $\mathrm{O}$ puede existir un factor tisular mamario que retarde e inhiba la involución glandular; o se puede deber a falla de las enzimas hepáticas requeridas para la glucoronidoconjugación de los estrógenos, paso indispensable en su eliminación oportuna.

En la primera consulta se puede hacer el diagnóstico presuntivo. El diagnóstico definitivo se sostiene sólo después de un seguimiento prudencial por un tiempo no menor a dos años, puesto que la hipertrofia mamaria puede ser una manifestación prematura de pubertad precoz (1).

El pezón y la aréola, al contrario de lo que sucede en la precodidad sexual, no aumentan de tamaño ni adquieren hiperpigmentación sino que permanecen en su estado infantil.

El tejido mamario se puede palpar granuloso y discretamente sensible (12). Una de las mamas puede desarrollarse ocho a doce meses antes que la otra.

La talla, lo mismo que la maduración esquelética estudiada por el carpograma, son normales para la edad cronológica.

Kenny y colaboradores encontraron una ligera elevación de LH y de FSH aun cuando insignificante y por ello le restaron todo valor a este hallazgo (17). Caufriez y colaboradores tampoco observaron modificaciones significativas ni de gonadotrofinas, ni de estradiol, ni de estrona, ni de prolactina plasmáticas (4).

La prueba de estimulación con GnRH puede dar una respuesta positiva para la FSH superior a la de una niña normal de 
Ia misma edad, en tanto que la respuesta de la LH es similar a la de las niñas testigos (16).

La citología funcional observada por el frotis vaginal o por el urocitograma no demuestran por lo general signos de estimulación estrogénica para la edad, si bien pueden encontrarse algunos extendidos hipoestrogénicos $(9,19,21)$.

Se han descrito algunos casos de lesiones cerebrales congénitas concomitantes con telarca precoz sin que se haya podido observar relación entre el fenómeno mamario y la patología congénita (23). Este caso no lo encontramos en ninguna de nuestras pacientes.

La menarca se presenta en el tiempo que le es propio acompañada de desarrollo sexual normal.

Con alguna frecuencia se ordena tomar mamografías para descartar patología tumoral mamaria o paramamaria, tan rara a esta edad. Sabemos que la mamografía está proscrita en niñas, en adolescentes y en mujeres jóvenes por el peligro que acarrea ya que la glándula mamaria recibe entre 2.5 y 3 rads por estudio y ésto hace que sólo en mujeres de edad avanzada los beneficios del examen radiológico superen al riesgo de los efectos cancerígenos (10).

La toma de biopsias para el diagnóstico de la alteración mamaria es innecesaria; hay el peligro de extirpar parcial o totalmente el botón mamario, hecho que impide el desarrollo normal posterior de esta mama (12).

Se debe diferenciar de la primera manifestación de una pubertad precoz; en este caso se acompaña de desarrollo de los caracteres sexuales secundarios, rata de cre- cimiento acelerado y aumento de la maduración esquelética, con urocitograma estrogénico.

Los tumores, paramamarios, especialmente los hemangiomas, son unilaterales y tienden a ganar la areola y los pezones; la piel presenta un color violáceo con discreta circulación colateral, y se obtiene sangre al puncionarlos (ver figura 2).

FIGURA No. 2

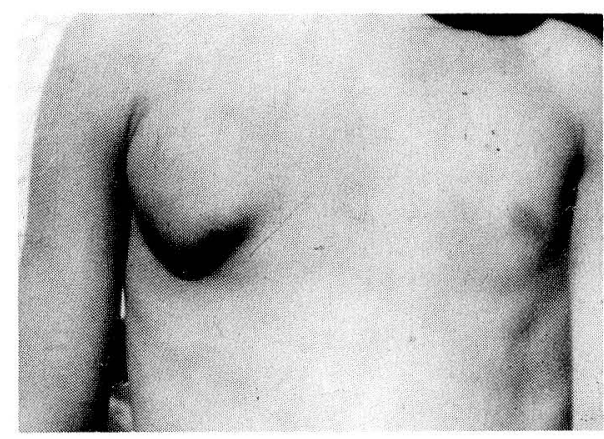

Niña de 6 años con una hemangioma paramamario, de un año de evolución.

Los tumores benignos del tejido mamario son una excepción y más raros aún los tumores malignos antes de los diez años $(11,14)$; la ecografía colabora en el diagnóstico.

La adipomastia se observa sólo en las obesas.

Los lipomas son unilaterales, circunscritos, de contornos regulares, bien definidos, superficiales, muy raros en las niñas delgadas.

Los quistes son una rareza, renitentes, diáfanos a la transiluminación y su diagnóstico se confirma con la punción. 


\section{TRATAMIENTO}

La telarca precoz no tiene tratamiento alguno médico ni quirúrgico. Es indispensable enseñar a los padres que es un problema benigno, generalmente pasajero que no requiere tratamiento, pero que necesita un seguimiento por un período nunca inferior a dos años, con control cada seis meses, para descartar la presencia de una pubertad precoz. Cuando se encuentra algún tumor paramamario se le debe extirpar teniendo el cuidado de respetar el botón mamario.

En cada control se debe practicar un examen clínico general con toma de talla,

\section{BIBLIOGRAFIA}

1. ARCANGELI, O. Telarca prematura. En: Ginecología pediátrica. Trastornos endocrinos. Ed. La Médica. Rosario, Argentina, 451, 1976.

2. BRONSTEIN, I.P. Y CASSORLA, E. Breast enlargement in pediatric practice. Med. Clin. N. Amer. 30: 121, 1946.

3. CAPRARO, V.J., BAYONET-RIVERA, N.P., ACETO, T. Jr. Y MACGILLIVRAY. Premature telarche. Obstet. and Gynecol. Survey, 26: 2, 1971.

4. CAUFRIEZ, A., GOVAERST, M., WOLTER, R., L'HERMITE, M. y ROBYN, C. Investigations endocriniennes en cas de gynecomastie isolée. En: Rapports Illemme Symposium internationale sur la Gynécologie de l'enfant et de l'adolescente. Lausanne. 165. 1976.

5. COLLET-SOLBERG, P.R. y GRUMBACH, M.M. A simplified procedure for de citología exfoliativa funcional, examen de genitales externos y tacto rectal con el fin de descartar masas ováricas (12).

\section{RESUMEN}

Se estudian doce niñas con telarca preCOz vistas en la Consulta de Ginecología Pediátrica del Hospital San Juan de Dios de Cúcuta y en mi clientela particular. Se analizan los hallazgos. Se insiste en que no se deben tomar mamografías a niñas y en el seguimiento a las pacientes por un período no inferior a dos años antes de formular un diagnóstico definitivo.

evaluating estrogen effects and the sex chromatin pattern in exfoliated cells in the urine. J. Pediatr. 66: 883, 1965.

6. DEWHURST, J. Breast disorders in children and adolescents. The Pediat. Clin. of N. Am. 28: 207, 1981.

7. DEWHURST, J. Isolate manifestations of precotious sexual development. En: Practical pediatric and adolescent gynecology. Marcel Dekker Inc. Ed. New York, 128: 1981.

8. DRESCH, C. ARNAL, M. y PRADER, A. Etude de 22 cas de développement prematuré isolé des seins ou "premature thelarche". Hely. Pediatr. Acta. 15: 585, 1960.

9. DUARTE-CONTRERAS, A. Telarca precoz. En: Ginecología de la niña y la adolescente. En prensa, 1987. 
10. DUARTE-CONTRERAS, A. Malformaciones $y$ patología de la glándula mamaria en adolescentes. Rev, Colomb. Obstet. Gynecol. 35: 99, 1984.

11. DUARTE y RAMIREZ. Cáncer de la mama en los niños. Arch. Cubanos de Cáncer. 10: 58, 1951

12. EMANS, S.J.H. y GOLDSTEIN, D.P. Te larquia prematura. En: Ginecología de la niña y de la adolescente. Ed. Médica y Técnica, Barcelona, 78, 1981.

13. GORINS, A., TERRIS, J. y THEVENET, $M$. Laglande mammaire chez la fillete. En: L'appareil génital féminin avant la puberté. Masson Cie, Paris. 287, 1971.

14. HABIBI, M. Deux cas de cancers du sein chez deux fillettes, I'une de 7 ans el l'autre de 9 ans. Bull. Assoc. Franc. Edit. Cancer. 1: 75, 1947.

15. HUFFMAN, J., DEWHURST, C.J., $V$ CAPRARO, V.J. The breast and its disorders in childhood and adolescence. En: The Gynecology of childhood and adolescence. W.B. Saunders Co. Philadelphia. 542, 1981.

16. JOB, J.C. y CANLORBE, P. Evaluation de la fonction hypophyso-gonadique dans les pubertés féminines normales et pathologiques. En: Rapports IIlemme Symposium international sur la gynécologie de l'enfant et de l'adolescente. Lausanne. 93. 1976
17. KENNY, F. M., MIDGLEY, A. R., JAFFE, R. B., GARCES, L. Y., VASQUEZ, A. Y TAYLOR, F.H. Radioinmmunoassayable serum Lh and FSH in girls with sexual precocity, premature thelarche and adrenarche. J. Clin. Endocr. 29: 1272, 1969

18. KRAUS, F.T. y NEWBECKER, R.D. Luteinzation in ovarian theca in infants and children. Amer. J. Clin. Path. 37: 689, 1962

19. LENCIONI, L.H. Y STAFFIERI, J.J. Urocytogram diagnosis of sexual precocity. Acta Cytol. (Baltimore). 13: 382. 1969.

20. SILVER, H.K. y SAMI, D. Premature Thelarche. Pediat. 34: 107, 1964.

21. SIGURJONSDOTTIR, T. J. Y HAYLES, A.B. Precoccius puberty. a report of 96 cases. Am. J. Dis. Child. 11: 309, 1968.

22. TALBOT, N.B., SOBEL, E.N., MCARTHUR, J.W. y CRAWFORD, J.D. Func tional endocrinology from birth through adolescence. Harvard University Press. Cambridge, 247, 1952.

23. THAMDRUP, E. Precocious sexual development. Charles C. Thomas, Springfield, 1961.

24. WILKINS, L. Diagnosis and treatment of endocrine disorders of childhood and adolescence. Charles C. Thomas, Springfield, ed 3, 1965. 